\title{
Highly differentiated CD4 T cells Unequivocally Identify Primary Resistance and Risk of Hyperprogression to PD- L1/PD-1 Immune Checkpoint Blockade in Lung Cancer
}

\begin{abstract}
Miren Zuazo-Ibarra ${ }^{1 \dagger}$, Hugo Arasanz ${ }^{1 \dagger}$, Gonzalo Fernández-Hinojal ${ }^{2 \dagger}$, María Gato-Cañas ${ }^{1 \dagger}$, Berta Hernández-Marín ${ }^{2}$, Maite Martínez-Aguillo², Maria Jose Lecumberri² ${ }^{2}$, Angela Fernández², Lucía Teijeira $^{2}$, Ruth Vera ${ }^{2 *}$, Grazyna Kochan ${ }^{1 *}$, and David Escors ${ }^{1,3 *}$
\end{abstract}

${ }^{1}$ Biomedical Research Center of Navarre-Navarrabiomed, Fundación Miguel Servet, Irunlarrea 3, 31008, Pamplona, Navarra, Spain.

${ }^{2}$ Department of Oncology, Hospital Complex of Navarre, Irunlarrea 3, 31008, Pamplona, Navarra, Spain.

${ }^{3}$ Division of Infection and Immunity, University College London, London WC1E 6JJ, United Kingdom.

*Correspondence to: Dr David Escors, d.escors@ucl.ac.uk or descorsm@navarra.es; Dr Grazyna Kochan, grazyna.kochan@navarra.es; Dr Ruth Vera, ruth.vera.garcia@navarra.es

$\dagger$ These authors contributed equally.

\section{Abstract}

The majority of lung cancer patients are refractory to PD-L1/PD-1 blockade monotherapy. This therapy may even accelerate progression and death in a group of patients called hyperprogressors. Here we demonstrate that the efficacy of PD-L1/PD1 blockade therapy relies on baseline circulating highly-differentiated CD28- CD27CD4 T cells ( $\mathrm{T}_{\mathrm{HD}}$ cells), which segregate patients in two non-overlapping groups. $\mathrm{T}_{\mathrm{HD}}$ cells in cancer patients mostly comprised of central memory subsets that potently coupregulated PD-1 and LAG3 upon antigen recognition. Low baseline $\mathrm{T}_{\mathrm{HD}}$ numbers unequivocally identified intrinsic non-responders and hyperprogressors, whom aberrantly responded to therapy with a potent systemic proliferative $\mathrm{T}_{\mathrm{HD}}$ cell burst. Responder patients showed significant reductions in systemic CD4 $\mathrm{T}_{\mathrm{HD}}$ cells throughout therapy linked to expansion of the CD28+ CD27+ CD4 T cell compartment. Quantification of $T_{H D}$ cells from peripheral blood samples prior to therapy allows identification of non-responders, hyperprogressors and responders, a critical issue in clinical oncology. These results place CD4 T cell responses at the center of anti-tumor immunity.

\section{Introduction}

PD-L1/PD-1 blockade is demonstrating remarkable clinical outcomes since its first clinical application in human therapy (Brahmer et al., 2012; Topalian et al., 2012). These therapies interfere with immunosuppressive PD-L1/PD-1 interactions by systemic administration of blocking antibodies. PD-L1 is frequently overexpressed by tumor cells and correlates with progression and resistance to proapoptotic stimuli (Azuma et al., 2008; Gato-Canas et al., 2017; Juneja et al., 2017). PD-1 is expressed in antigenexperienced $\mathrm{T}$ cells and interferes with $\mathrm{T}$ cell activation when engaged with PD-L1 
(Chemnitz et al., 2004; Karwacz et al., 2011).

A significant number of lung cancer patients are intrinsically refractory to PDL1/PD-1 immune checkpoint blockade therapies. Indeed, there is accumulating evidence that PD-L1/PD-1 blockade might even have deleterious effects by accelerating disease and death in a group of patients called hyperprogressors (Champiat et al., 2017; Saada-Bouzid et al., 2017). Currently, there is no way of identifying them before the start of therapy. Hence, stratification of patients into hyperprogressors, non-responders and potential responders is of critical importance (Topalian et al., 2016) especially when the relevance of tumor PDL1 expression as a predictive biomarker is still under debate, at least for some cancer types (Grigg and Rizvi, 2016). Other biomarkers such as the immunoscore (Galon et al., 2006), interferon gene signatures, mutational load and microsatellite instability require relatively large biopsies (Jamieson and Maker, 2017; Vranic, 2017). These techniques are often difficult to implement in a clinical context, and the retrieval of representative biopsies can sometimes be challenging.

In addition, the impact of $\mathrm{T}$ cell terminal differentiation in aged patients is often overlooked in cancer immunotherapies. Highly differentiated human $\mathrm{T}$ cells $\left(\mathrm{T}_{\mathrm{HD}}\right.$ ) accumulate with age by a progressive loss of CD27 and CD28 expression (Lanna et al., 2014). $\mathrm{T}$ cells are classified as poorly differentiated (CD28+ CD27+ $\mathrm{T}_{\mathrm{PD}}$ cells), intermediately differentiated cells which lose CD27 expression (CD28+ CD27- TINT cells) and $\mathrm{T}_{\mathrm{HD}}$ cells (CD28- CD27-). In most cases $\mathrm{T}_{\mathrm{HD}}$ cells correspond to terminally differentiated $\mathrm{T}$ cells with effector activities, also known as EMRA or senescent cells (Lanna et al., 2017; Lanna et al., 2014) (Fig. 1A). Although dysfunctional to some degree due to reduced expression of CD28 and CD27 coreceptors, these cells do constitute a large pool of antigen-specific T cells with potent effector activities when mobilized (Lanna et al., 2017; Lanna et al., 2014). Indeed, PD1 blockade can recover some effector activities of CD8 $\mathrm{T}_{\mathrm{HD}}$ cells in vitro (Henson et al., 2015). However, the clinical impact of PD-L1/PD-1 immune checkpoint inhibitor therapy in $\mathrm{T}_{\mathrm{HD}}$ cells and its relationship with objective clinical responses have not been addressed yet.

Here we focused on understanding the impact of $\mathrm{T}_{\mathrm{HD}}$ cells over clinical responses in NSCLC patients undergoing PD-L1/PD1 immune checkpoint blockade therapy.

\section{Results}

\section{Baseline CD4 $\mathbf{T}_{\mathrm{HD}}$ cells separate NSCLC patients in two non-overlapping groups}

Systemic circulating $T_{H D}$ cells were quantified in a cohort of 45 NSCLC patients and healthy age-matched donors $(64.8 \pm 8.3$ vs $68.60 \pm 8$ years old, mean \pm standard deviation, SD). Cancer patients showed highly significantly increased numbers of CD4 $\mathrm{T}_{\mathrm{HD}}$ cells $(\mathrm{P}<0.0001)$ but not of CD8 $\mathrm{T}_{\mathrm{HD}}$ cells. Importantly, patients were distributed in two non-overlapping groups according to $\mathrm{CD} 4 \mathrm{~T}_{\mathrm{HD}}$ baseline numbers (Fig. 1B); Patients with above-average (G1 patients, $72.2 \% \mathrm{~T}_{\mathrm{HD}} \quad[67.2-76.8,95 \%$ confidence interval (C.I.), $\mathrm{N}=21]$ ) and below-average numbers (G2 patients, $28.2 \% \mathrm{~T}_{\mathrm{HD}}$ [24-32.5, 95\% C.I., $\left.\mathrm{N}=24\right]$ ). Accordingly, NSCLC patients showed very significantly lower numbers of CD28+ CD27+ CD4 T cells $(\mathrm{P}<0.001)$ (Fig. 1B). As CD4 $\mathrm{T}_{\mathrm{HD}}$ cells segregated patients in two separate groups, we decided to characterize them at baseline and throughout treatment.

Surprisingly, CD4 $\mathrm{T}_{\mathrm{PD}}, \mathrm{T}_{\mathrm{INT}}$ and $\mathrm{T}_{\mathrm{HD}}$ cells consisted of a mixture of differentiation phenotypes, including naïve/stem memory (CD62L+ CD45RA+), central memory (CM, CD62L+ CD45RA-), effector memory (EM, CD62L- CD45RA-) and effector cells (EF, CD62L ${ }^{\text {low/neg }}$ CD45RA+ or EMRA cells), independently on whether they came from G1 or G2 patients (Fig. 1C, 1D). $C D 4 T_{H D}$ were enriched in cells with 
central/effector memory phenotypes but not in EMRA cells, suggesting that these CD28CD27- $\mathrm{T}$ cells were not truly terminally differentiated or senescent, although probably dysfunctional. To test this hypothesis, PD-1 expression was evaluated in systemic CD4 $\mathrm{T}_{\mathrm{HD}}$ cells from NSCLC G1 and G2 patients. No significant PD-1 surface expression was observed in these cells (Fig. 1E). This was surprising as constitutive expression of markers such as PD-1 or LAG3 are trademarks of dysfunctional $\mathrm{T}$ cells in cancer. However, when CD4 T cells were stimulated by coincubation with human lung A549 adenocarcinoma cells expressing a membrane-bound anti-CD3 antibody, CD4 $\mathrm{T}$ cells from NSCLC patients showed a strong co-up-regulation of PD-1 and LAG3 (Fig. 1E). A different expression pattern was observed without PD-1/LAG-3 coexpression when CD4 T cells from healthy donors were evaluated, in which PD-1 or LAG-3 represent activation markers. Moreover, PD-1 up-regulation was very significantly $(\mathrm{P}<0.001)$ pronounced in the more differentiated CD4 subsets, and especially in T cells from NSCLC patients (Fig. 1F). 
A

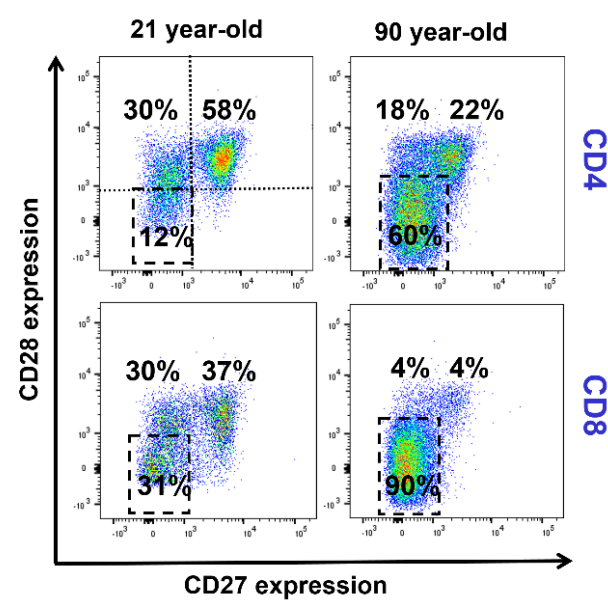

C

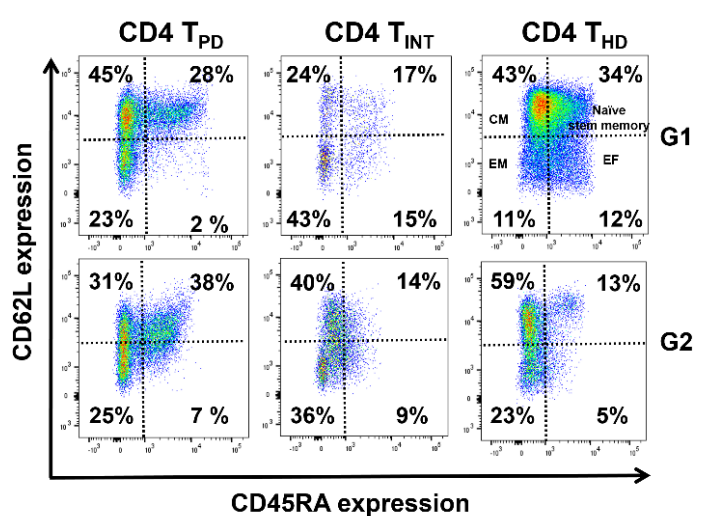

E

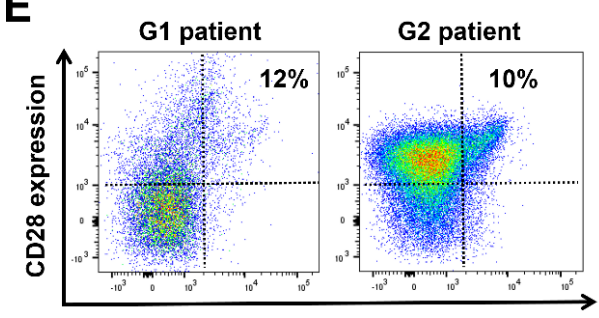

PD1 expression

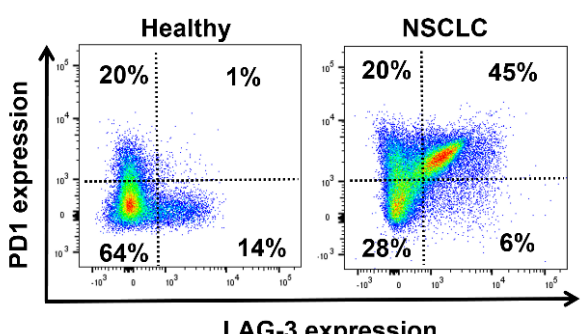

B
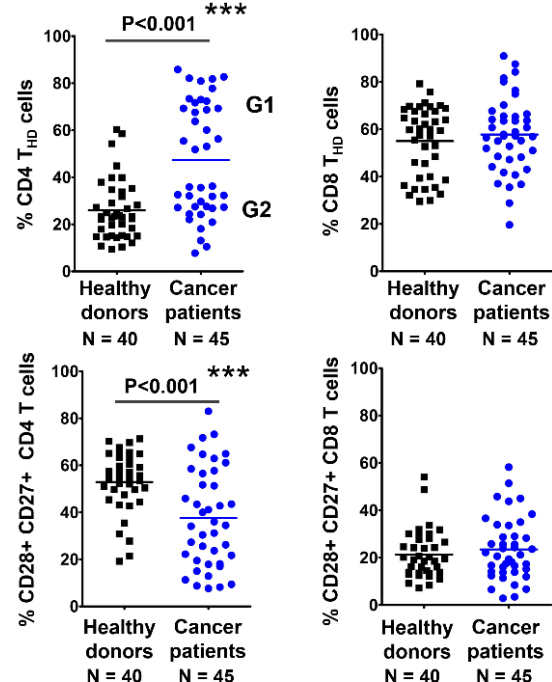

D
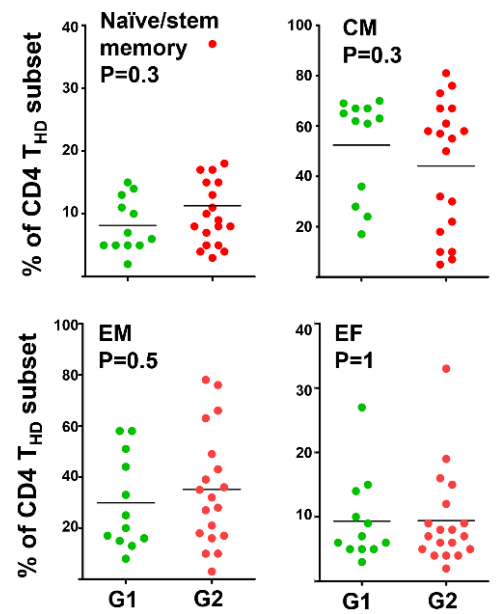

Patient groups by baseline CD4 $\mathrm{T}_{\mathrm{HD}}$ numbers

$\mathbf{F}$

PD1 up-regulation after TCR stimulation

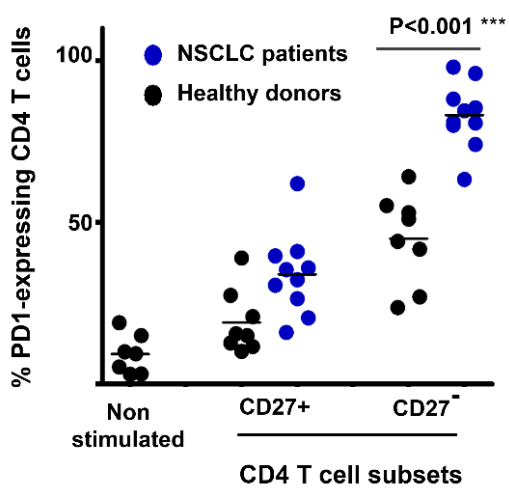

Figure 1. Systemic CD4 $T_{H D}$ cells in NSCLC patients treated with PD-L1/PD-1 immune checkpoint inhibitors. (A) Flow cytometry density plots of CD4 (upper graphs) and CD8 T cells (lower graphs) from young (left graphs) and senior (right graphs) healthy donors, according to CD28CD27 expression profiles. Dashed lines within the upper left graph show the gates used to quantify poorly differentiated $(C D 28+C D 27+)$, intermediately differentiated $(C D 28+C D 27-)$ and $T_{H D}$ cells (CD28-CD27-). $T_{H D}$ cells are highlighted in each graph by a square. Percentages of each cell subset are indicated within the graphs. (B) Circulating highly differentiated CD4 / CD8 (upper graphs), and 
poorly differentiated CD4 / CD8 (lower graphs) subsets in age-matched healthy donors or NSCLC patients before undergoing immunotherapies. G1 and G2, groups of patients classified according to high $T_{H D}$ cells $(G 1)$ and low $T_{H D}$ cells $(G 2)$. N, number of patients used for analyses. Relevant statistical comparisons are shown by the U of Mann-Whitney test. (C) Flow cytometry density graphs of CD4 $T_{H D}$ from NSCLC G1 patients (upper graphs) or G2 patients (lower graphs) according to CD62L-CD45RA expression profiles. Dotted lines separate quadrants according to nä̈ve/stem memory, central memory $(C M)$, effector memory $(E M)$ and effector phenotypes $(E F)$, which include the percentage of cells in each quadrant. (D) As in (C) but representing data as scatter plot graphs for each patient classified according to G1 or G2 patient groups as indicated. Statistical comparisons performed by the $U$ of Mann-Whitney. (E) Flow cytometry density plots of circulating CD4 T cells in G1 patients (upper left graph) and $G 2$ patients (lower upper right graph) according to CD28-PD-1 expression profiles. The percentage of $C D 28+P D-1+C D 4 T$ cells is indicated. The lower flow cytometry density graphs represent PD-1 and LAG3 up-regulation in CD4 T cells from a healthy donor (left graph) or an NSCLC patient (right graph) after $T$ cell receptor (TCR) activation by 4549 cells expressing a membrane bound anti-CD3 single-chain antibody. Percentages of cells within each quadrant are indicated. (F) Scatter plots representing the up-regulation of PD-1 after TCR activation as in $(E)$ in healthy donors and NSCLC patients, separated into CD27+ and CD27-CD4 T cells. Relevant statistical comparisons are indicated, by the U of Mann Whitney. *** represents highly significant differences, respectively.

\section{Baseline CD4 $\mathrm{T}_{\mathrm{HD}}$ numbers discriminate responses to PD-L1/PD-1 immune checkpoint blockade therapies \\ 34 of the NSCLC patients continued with nivolumab, pembrolizumab or} atezolizumab treatments following their current indications, and at the end of the study responders accounted to $20 \%$ (7 out of 34), consistent with the published efficacies for these agents (Herbst et al., 2016; Horn et al., 2017; Rittmeyer et al., 2017). To evaluate the impact of circulating CD4 $\mathrm{T}_{\mathrm{HD}}$ over immunotherapies, we monitored CD4 $\mathrm{T}_{\mathrm{HD}}$ cell numbers throughout therapy from routine small fresh blood samples. Strikingly, CD4 $\mathrm{T}_{\mathrm{HD}}$ cell values before the start of therapy unequivocally discriminated patients according to responses $(\mathrm{P}=0.0008)$ (Fig. 2A). $\mathrm{G} 2$ patients ( $\mathrm{T}_{\mathrm{HD}}$ values below $40 \%$ ) were all progressors [19 patients with $26.9 \% \pm 7.8$ baseline $\mathrm{T}_{\mathrm{HD}}$ cells, (23-30.8, $95 \%$ C.I.)], while responders accounted to $47 \%$ of $\mathrm{G} 1$ patients with $\mathrm{T}_{\mathrm{HD}}$ values above $40 \%$ [ 7 out of 15 patients with $71.5 \% \pm 9$ baseline $\mathrm{T}_{\mathrm{HD}}$ cells, (63-80, 95\% C.I.)]. Reciprocally, patients with CD28+ CD27+ CD4 $\mathrm{T}$ cell baseline values above $40 \%$ were all progressors (Fig. 2B) $(\mathrm{P}=0.005)$. Therefore, we defined patients with a "positive" baseline profile as those belonging to G1, while G2 represented patients with a "negative" baseline profile. 
A

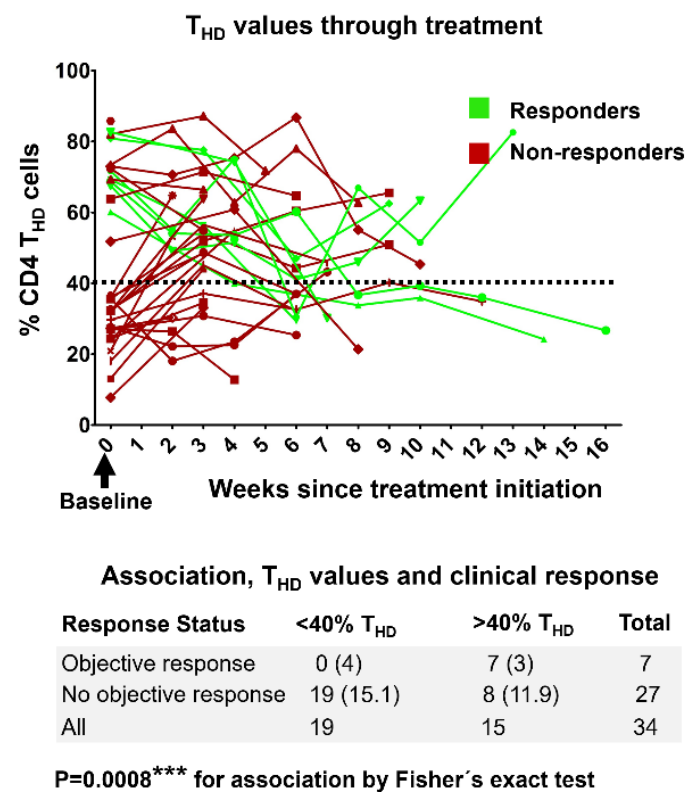

B

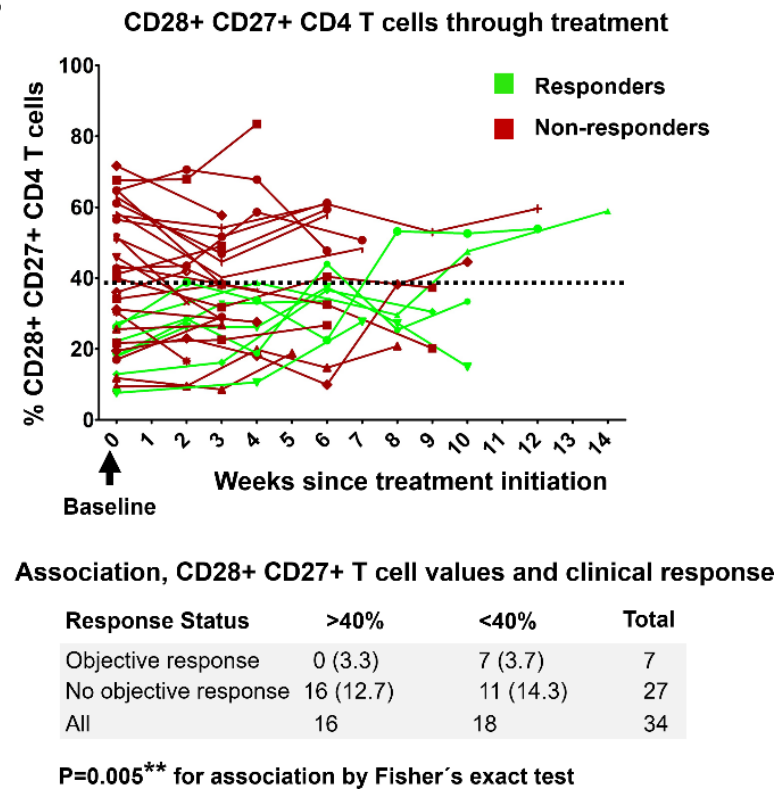

Figure 2. Dynamic changes of systemic CD4 $T_{H D}$ and CD28+CD27+CD4T cells throughout treatment.

(A) Percentage of circulating CD4 $T_{H D}$ cells in treated patients along therapy from baseline (arrow, time 0). In green, patients with objective responses. In red, non-responders. Dotted line, the lowest discriminating cut-off value (40\%) separating G1 from G2 patients. No responders were observed below this cut-off value in the cohort study. Below the graph, correlation of responses to $T_{H D}$ baseline values by the Fisher's exact test. (B) Same as (A), but representing CD4 $T_{P D}(C D 28+C D 27+)$ cells.

Immune checkpoint blockade therapy induces unique dynamic changes in circulating CD4 $\mathbf{T}_{\mathrm{HD}}$ cells that correlate with clinical responses

Immune checkpoint inhibitors strongly affected CD4 $\mathrm{T}$ cell populations within the first cycle of treatment, and two main distinct dynamic profiles were identified. Pattern 1 or " $\mathrm{T}_{\mathrm{HD}}$ burst" consisted in a highly significant increase in systemic CD4 $\mathrm{T}_{\mathrm{HD}}$ cells $[12.4 \%$ increase, $(6.2,18.5) 95 \%$ CI, $\mathrm{N}=27, \mathrm{P}<0.0001$, one-tailed paired $\mathrm{t}$ test)] and was associated to tumor progression without exception in our cohort of patients (Fig. 3A, 3C, 3D). Pattern 2 or $\mathrm{T}_{\mathrm{HD}}$ decrease was characterized by very significant reduction in systemic $\mathrm{T}_{\mathrm{HD}}$ cells $[-14.4 \%, \quad(-8,-21), \quad 95 \% \quad \mathrm{CI}, \quad \mathrm{N}=7$, $\mathrm{P}<0.0001]$, concomitant to an expansion of CD28+ CD27+ CD4 T cells and primarily associated to tumor regression (Fig. 3B, 3C, 3D). There was a very highly significant correlation $(\mathrm{P}=0.0001)$ between $\mathrm{T}_{\mathrm{HD}}$ changes and therapeutic outcome (Fig. 3D). 
A

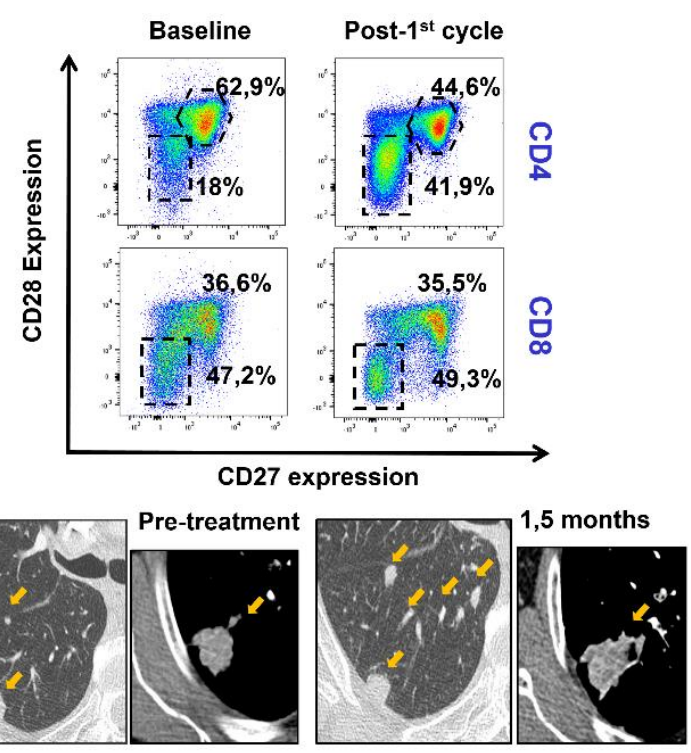

C

$T_{\mathrm{HD}}$ percentages from baseline to post- $1^{\text {st }}$ cycle

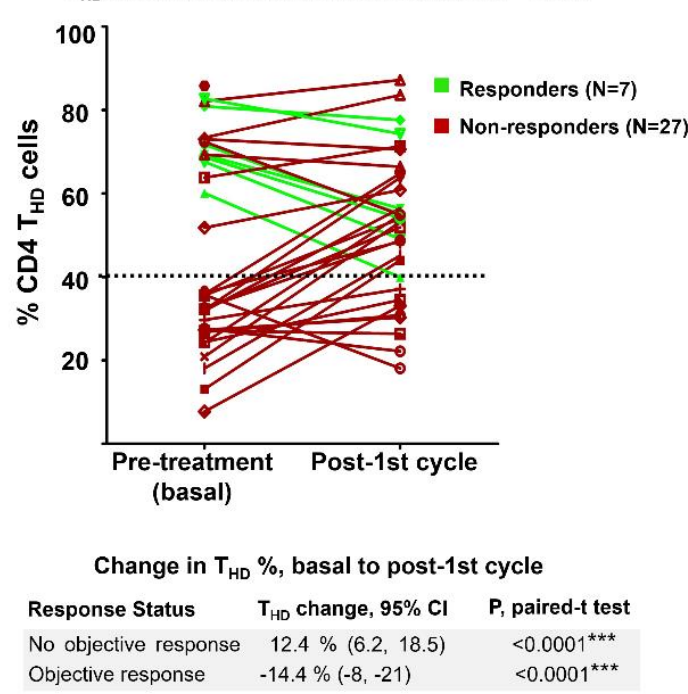

B

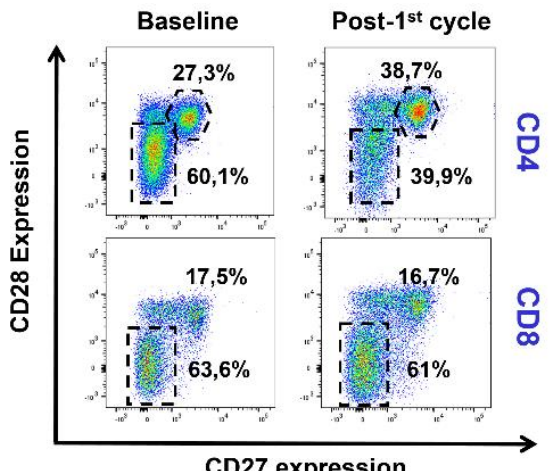

CD27 expression

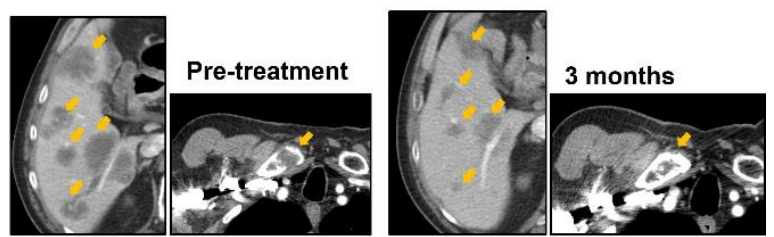

D

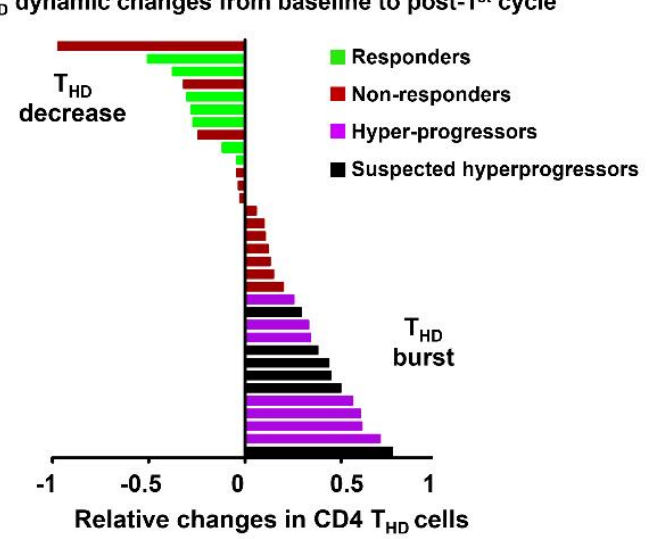

Association, $\mathrm{T}_{\mathrm{HD}}$ change and clinical response

$\begin{array}{llll}\text { Response Status } & \text { Decrease } & \text { Increase } & \\ \text { Objective response } & 7(2.7) & 0(4.3) & 7 \\ \text { No objective response } & 6(10.3) & 21(16.7) & 27 \\ \text { All } & 13 & 21 & 34 \\ P=0.0001^{* * \star} \text { for association by Fisher's exact test } & \end{array}$

Figure 3. Systemic CD4 $T_{H D}$ dynamic changes and clinical responses. (A) Clinical case of a progressor with a G2 baseline profile associated to a " $T_{H D}$ burst" response. Flow cytometry density plots show baseline and post-first cycle CD4 (upper graphs) and CD8 T cells (lower graphs). Highly differentiated and poorly differentiated CD4 T cells are highlighted within doted square gates and hexagonal gates, respectively, together with their percentage. Below, CT scans of lung metastases and primary tumor progressing from baseline (left scans) after one month and a half (right scans) of therapy. Lesions are indicated with arrows. (B) Clinical case of a responder with a G1 baseline profile associated to systemic $T_{H D}$ reduction. CT scans show regression of hepatic and clavicular bone metastases (indicated with arrows) before (left scans) and after 3 months (right scans) of therapy. (C) Change in circulating CD4 $T_{H D}$ cells from baseline (pre-treatment) to post-first cycle of therapy. In red, progressors, in green objective responders. The $40 \%$ cut-off value separating G1 from G2 patients is shown. Below, increase and decrease in $T_{H D}$ cells within reponders or non-responders, as tested by paired t tests. (D) Waterfall plot of the relative changes in CD4 $T_{H D}$ cells in each patient from baseline to post-first cycle of therapy. Green bars, patients with objective responses; red bars, non-responders; purple, radiologically-confirmed hyperprogressors; black, suspected hyperprogressors. Below, correlation of $T_{H D}$ cell change with clinical outcome by the Fisher's exact test. 
To find out if $\mathrm{T}_{\mathrm{HD}}$ bursts were the result of active proliferation of CD4 $\mathrm{T}_{\mathrm{HD}}$ cells from baseline to post-first cycle of therapy, Ki67 expression was analyzed by intracellular flow cytometry in $\mathrm{T}_{\mathrm{HD}}$ cells from nonresponder and responder patients (Fig. 4A, 4B). $T_{H D}$ cells in non-responders showed a significant increase in Ki67 expression. In contrast, responders showed a markedly decrease in $\mathrm{T}_{\mathrm{HD}} \mathrm{Ki67}$ expression from baseline to post-first cycle of therapy, together with increased Ki67 expression in the CD28+ $\mathrm{CD} 27+\mathrm{CD} 4 \mathrm{~T}$ cell compartment (Fig. 4C). These results indicated that $\mathrm{T}_{\mathrm{HD}}$ bursts were likely the result of systemic $T_{H D}$ proliferation.
To test whether $\mathrm{T}_{\mathrm{HD}}$ bursts occurred in specific subsets, the changes from baseline to post-first cycle of therapy were studied only in patients exhibiting $\mathrm{T}_{\mathrm{HD}}$ bursts, and compared to those from responder patients. Although the changes were not significant either in responders (with $\mathrm{T}_{\mathrm{HD}}$ decrease) or non-responders exhibiting $\mathrm{T}_{\mathrm{HD}}$ bursts with the current number of patients, there were clear trends. CD4 $\mathrm{T}_{\mathrm{HD}}$ bursts were enriched in $\mathrm{CM}$ subsets in detriment of more differentiated effector subsets (EM and EF cells) (Fig. 4D). In contrast, CD4 $\mathrm{T}_{\mathrm{HD}}$ cells that remained in responders post-first cycle of therapy were enriched in EM and EF cells.
A

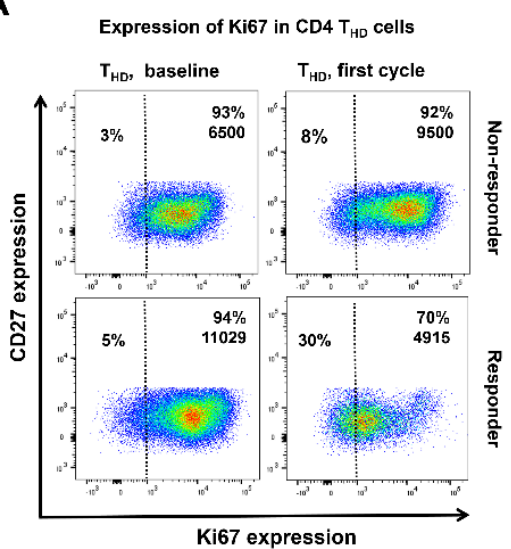

B

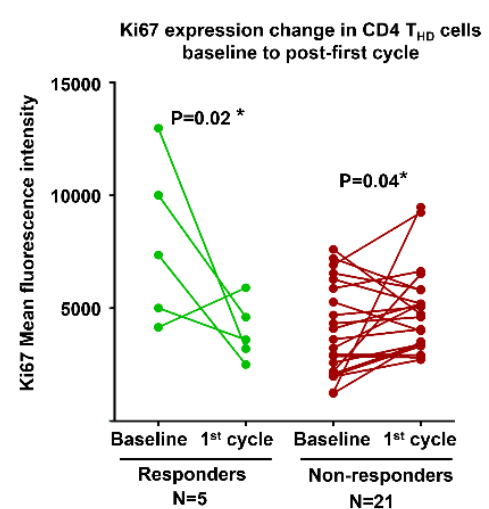

C
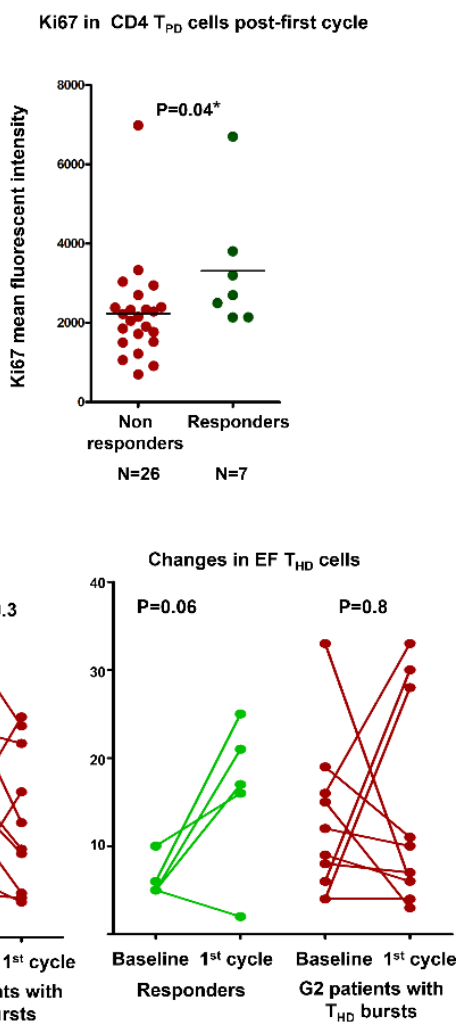

Figure 4. Proliferation of CD4 $T_{H D}$ in responders and non-responders. (A) Flow cytometry density plots of Ki67 expression in $T_{H D}$ cells from a progressor (upper two graphs) and a responder (lower two graphs) at baseline and post-first cycle of therapy as indicated. Percentage and Ki67 mean fluorescent intensities in proliferating $T_{H D}$ cells are indicated within the graphs. (B) Change in Ki67 expression in $C D 4 T_{H D}$ cells from responders and non-responders, as indicated. Only data was plotted from patients in which baseline and first-cycle Ki67 values were available. Paired t-tests were performed to compare the change from baseline to post-first cycle of therapy. (C) Dot plots of Ki67 
expression in CD28+CD27+CD4 T cells (right graph) in non-responders and responders as indicated, in our cohort study. Differences were tested by the U of Mann-Whitney test. (D) Dot plots of changes in the percentage of circulating $T_{H D}$ differentiation subsets (as indicated) from baseline to post-first cycle of therapy, in patients exhibiting $T_{H D}$ bursts compared to responders. Data from patients with available CD62L-CD45RA profiles were used in the analyses. Relevant statistical comparisons are shown within the graphs, using paired t tests; $N$, number of patients used in the analyses; * indicate significant differences.

CD4 THD bursts define primary resistance to PD-L1/PD-1 blockade and hyperprogression

All G2 patients showed tumor progression (Fig. 5A). Within this group, hyperprogressors were identified following the definition by Sâada-Bouzid et al (Saada-Bouzid et al., 2017) but using as a threshold a tumor growth kinetics ratio equal or superior to 5 (Fig. 5B). We confirmed that a negative $\mathrm{T}_{\mathrm{HD}}$ baseline profile significantly correlated with radiologically-confirmed hyperprogressors $(\mathrm{P}=0.01)$ (Fig. 5C) whom showed highly significant $\mathrm{T}_{\mathrm{HD}}$ bursts $(\mathrm{P}=0.0001)$ following the first cycle of therapy (Fig. 5D). Six patients were identified as probable hyperprogressors by clinical parameters, whom either died before radiological confirmation or the disease was not evaluable by radiological criteria. Their immunological profiles were consistent with radiologically-confirmed hyperprogressors (Fig. 5C and 5D). All of them experienced early progression of disease compared to the rest (median progression-free survival $(\mathrm{mPFS})=6$ weeks [5.7-6.3, 95\% C.I.] versus 8.9 weeks [4.6$13.1,95 \%$ C.I.], $\mathrm{p}=0.002$ ).

The agreement between the radiological criterium and the immunological profiling was significant in the identification of hyperprogression by a kappa test $(\kappa=0.742)$. Hence, a G2 profile associated to significant " $\mathrm{T}_{\mathrm{HD}}$ bursts" objectively characterized hyperprogressive disease in NSCLC patients without being influenced by previous tumor burden or dynamics. 
A

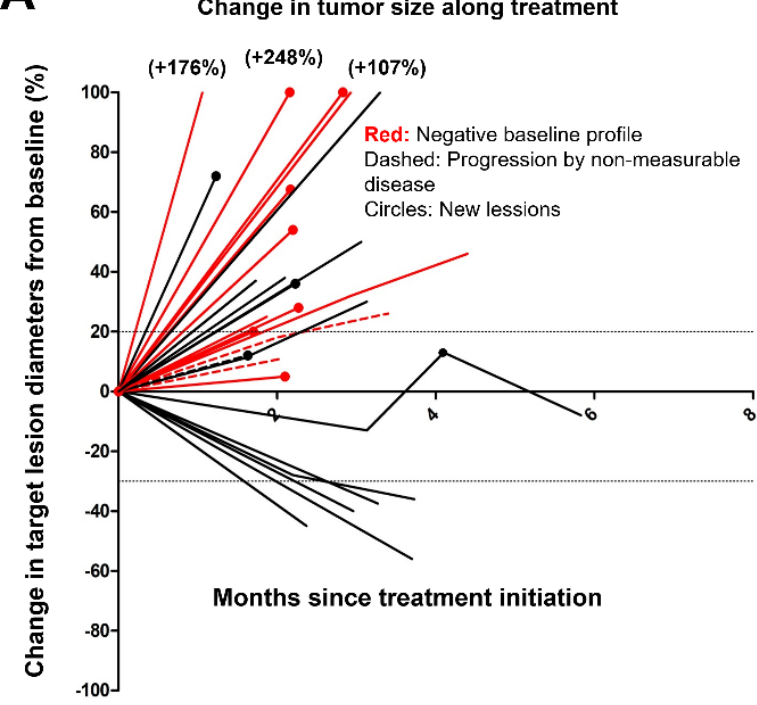

C

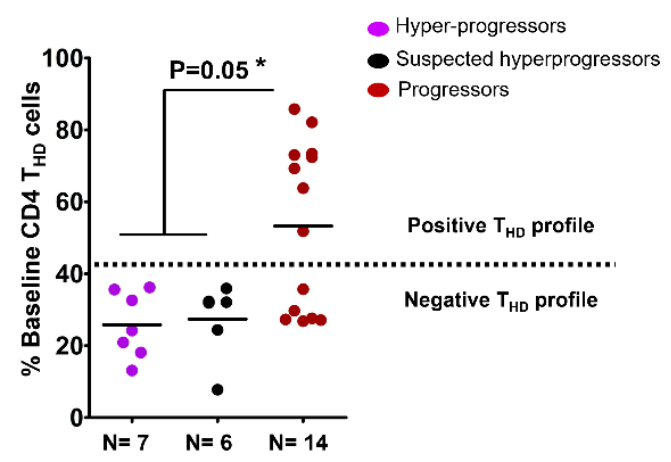

Association, baseline $T_{H D}$ profiles and hyperprogression

$\begin{array}{lccc}\text { Response Status } & \text { Negative profile } & \text { Positive profile } & \text { Total } \\ \text { Hyperprogression } & 7(4.3) & 0(2.7) & 7 \\ \text { Progression } & 6(8.7) & 8(5.3) & 14 \\ \text { All } & 13 & 8 & 21\end{array}$

$P=0.01$ * for association by Fisher's exact test
B

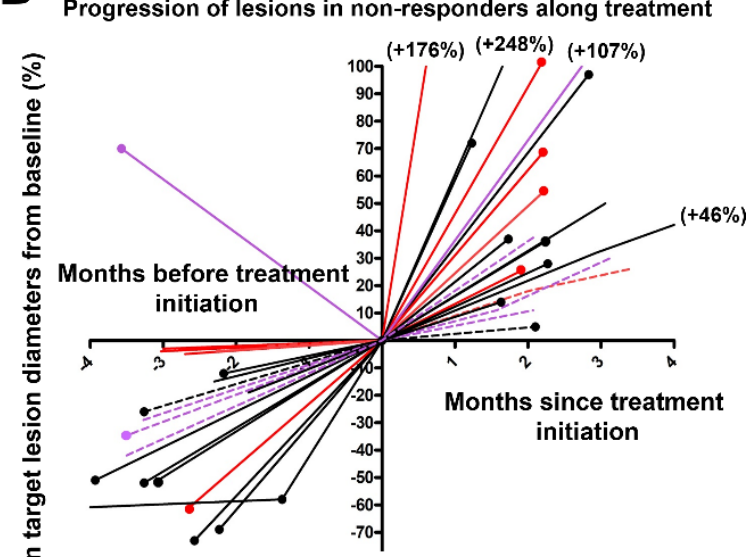

Purple: Immunological-only hyperprogressors Red: Radiological and immunological hyperprogressors Black: Progressors

Dashed: Paradoxical progression or non-measurable disease Circles: New lesions

D

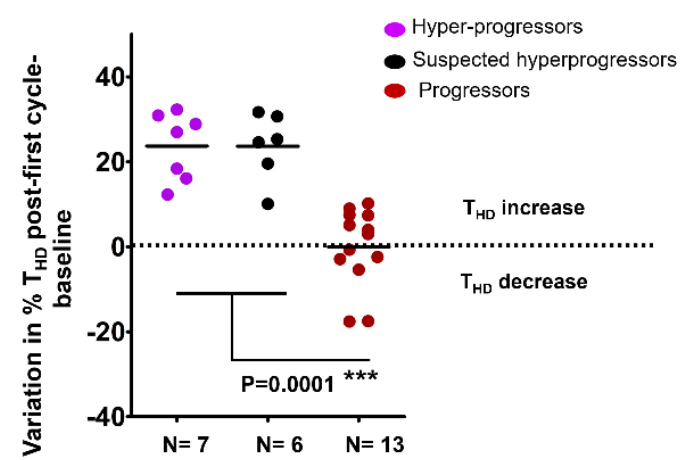

$\begin{array}{llll}\text { Association, } \mathbf{T}_{\mathrm{HD}} \text { burst and radiological hyperprogression } \\ \text { Response Status } & \mathbf{T}_{\mathrm{HD}} \text { burst } & \text { No burst } & \text { Total } \\ \text { Hyperprogression } & 7(4.9) & 0(2.1) & 7 \\ \text { Progression } & 7(9.1) & 6(3.9) & 13 \\ \text { All } & 14 & 6 & 20\end{array}$

$P=0.03^{*}$ for association by Fisher's exact test

Figure 5. $T_{H D}$ immunological profiles and hyperprogressive disease. (A) Spider plot of change in target lesions. Red, patients that started therapy with a negative baseline profile. These patients presented progressive disease, or growth of lesions. (B) Spider plot of change in target lesions of progressors before and after the start of immunotherapy. (C) Scatter plot of baseline $T_{H D}$ cell values in hyperprogressors, suspected hyperprogressors and progressors, as indicated. Dotted line shows the $40 \%$ cut-off value separating G1 from G2 patients. Below, correlation of baseline $T_{H D}$ cells with radiologically-confirmed hyperprogressors by a Fisher's exact test. Suspected hyperprogressors were excluded. (D) Scatter plot of changes in CD4 $T_{H D}$ percentage from baseline to post-first cycle of therapy in radiologically-confirmed hyperprogressors, suspected hyperprogressors and progressors. Dotted line separates $T_{H D}$ increases from decreases. Differences were tested by $U$ of Mann-Whitney test. Suspected hyperprogressors were excluded. Below, correlation of $T_{H D}$ burst with radiologicallyconfirmed hyperprogressors by a Fisher's exact test.. $N$, number of patients in each group; Comparisons of CD4 $T_{H D}$ cells and changes in CD4 $T_{H D}$ cells were performed with the U of MannWhitney excluding suspected hyperprogressors; $N$, number of patients used in the analyses; *,**, ** indicates significant, very and highly significant differences. 


\section{Baseline THD numbers constitute a strong and reliable predictive biomarker for primary resistance and hyperprogression with practical clinical application}

To improve specificity even at the cost of a lower sensitivity for identification of intrinsic non-responders, the negative baseline $\mathrm{T}$ cell profile was refined as the combination of CD4 $\mathrm{T}_{\mathrm{HD}}<40 \%$ and CD28+ CD27+CD4 T cells $>40 \%$. In patients with this strict negative baseline profile, the mPFS was only 6.0 weeks ( $95 \%$ C.I., 5.7 to 6.3) (Fig. 6A). A comparison of negative and non-negative baseline profiles showed hazard ratios for disease progression or death that favored the latter [3.39 (1.4-8.17; 95\% C.I.) $\mathrm{P}=0.007$ ] (Fig. 6A). Patients were also stratified into hyperprogressors according to the immunological criteria defined in this study, with an mPFS of only 6 weeks (5.7-6.3; 95\% C.I.). Hazard ratios for disease progression or death favored patients with non-hyperprogressive $\mathrm{T}$ cell dynamics $[3.89$ (1.58-9.58; 95\% C.I.) $\mathrm{P}=$ 0.002] (Fig. 6B). To discard that the baseline $\mathrm{T}_{\mathrm{HD}}$ profile was a prognostic instead of a predictive factor, the median time elapsed from diagnosis to enrolment for immunotherapy was evaluated in patients with negative or positive $\mathrm{T}_{\mathrm{HD}}$ profiles. There were no significant differences between the two groups, confirming the predictive and not the prognostic value of $\mathrm{T}_{\mathrm{HD}}$ profiling (10.9 months vs 9.8 months, $\mathrm{P}=0.9899$ ) (Fig. 6C). ROC analysis was performed in our patient cohort to test the robustness of $\mathrm{T}_{\mathrm{HD}}$ quantification prior to therapy as a predictive biomarker (Fig. 6D). The association of baseline $\mathrm{T}_{\mathrm{HD}}$ cells with clinical output was very significant $(\mathrm{R}=0.84, \mathrm{P}=0.006)$, with a cut-off value of $<57.7 \%$ to achieve $100 \%$ specificity and $75 \%$ sensitivity. 
A

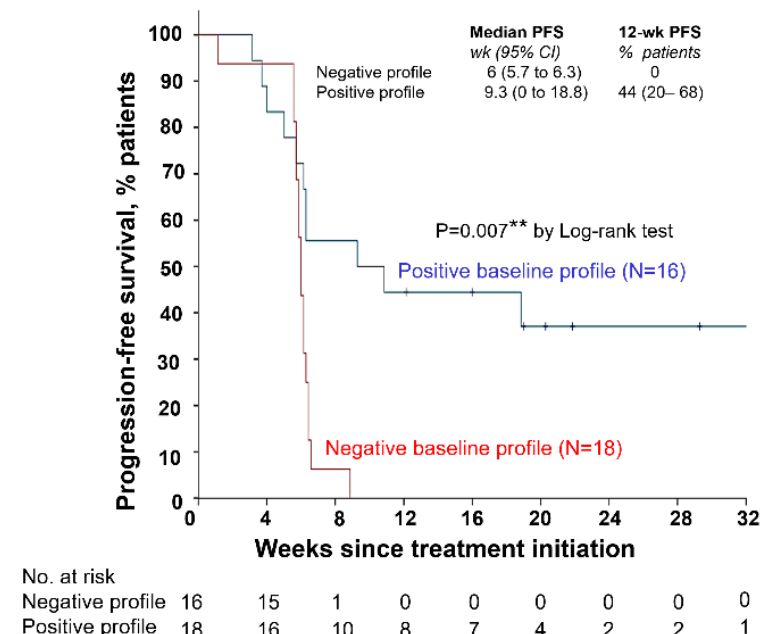

C

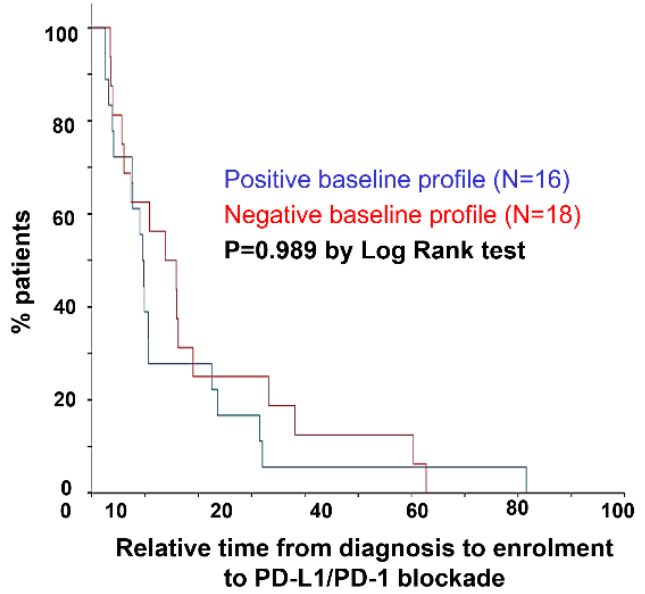

E

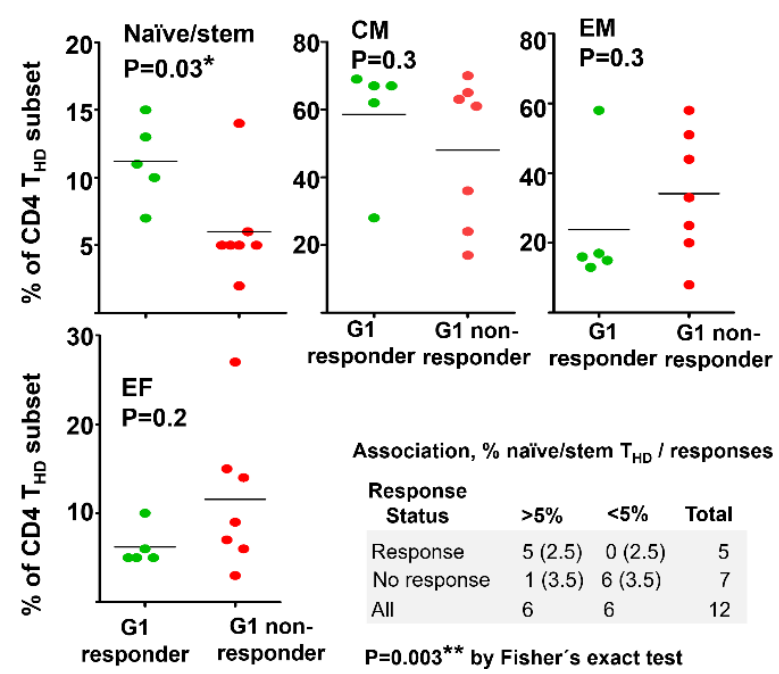

B

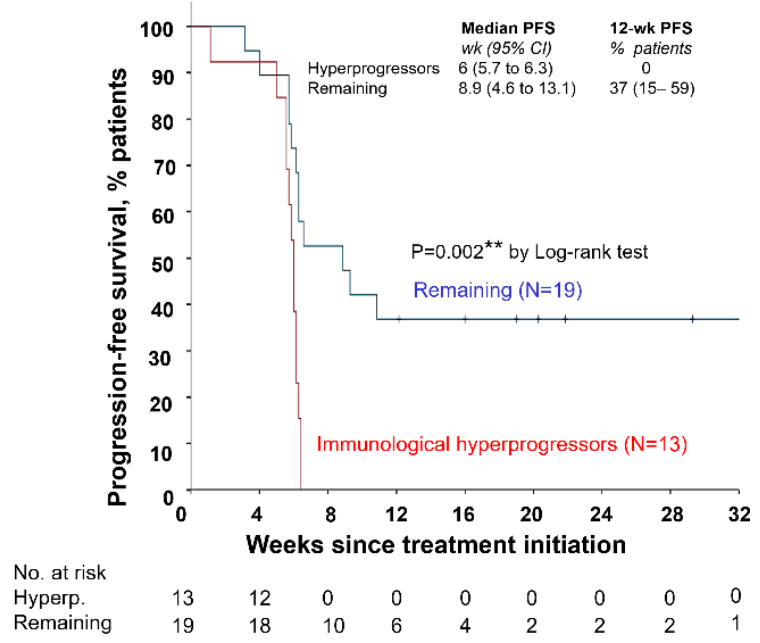

D

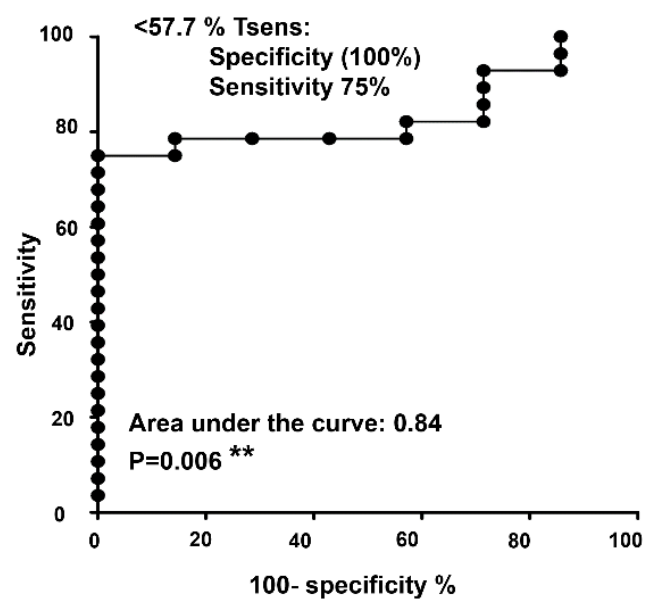

$\mathbf{F}$

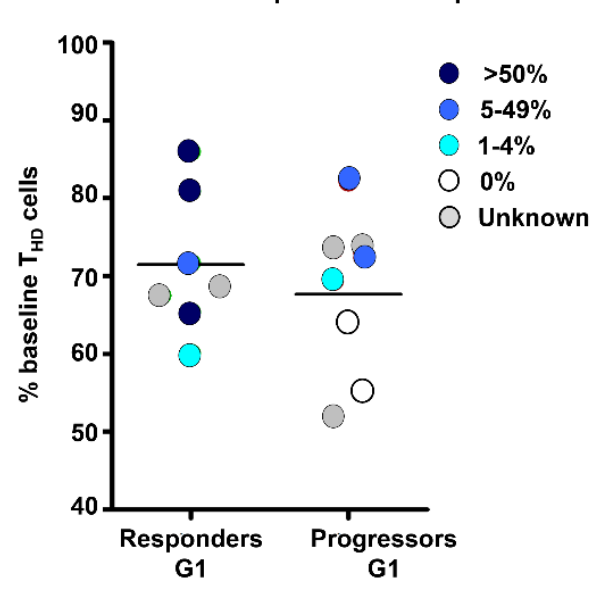

Figure 6. $T_{H D}$ profiling as a predictive biomarker of responses. (A) Kaplan-Meier plot for PFS in patients undergoing immune checkpoint inhibitor therapies stratified by strict baseline negative and positive T cell profiles as defined in the text. Patients starting therapy with a negative baseline profile had an overall response rate (ORR) of $0 \%$ and all experienced progression or death by week 9. ORR was $38.9 \%$ for patients with a positive baseline profile, and the 12-week PFS was 44\%. (B) As in (A) 
but stratifying patients according to hyperprogression assessed by immunological criteria (negative CD4 $T_{H D}$ baseline profile-significant $T_{H D}$ burst). Patients classified as immunological progressors progressed or died by week 7. (C) Kaplan-Meier plot of time of diagnosis to enrolment in patients stratified by positive or negative $C D 4 T_{H D}$ profiles as indicated, demonstrating no significant prognostic value. (D) ROC analysis of baseline CD4 $T_{H D}$ quantification as a predictive biomarker. Within the graph, highest cut-off value of CD4 $T_{H D}$ cells to discriminate intrinsic responders with $100 \%$ specificity. **, indicates very significant differences. (E) Scatter plots of percentages of baseline THD differentiation subsets as indicated on top of each graph in responders and non-responders from G1 patients. Statistical comparisons were performed with the U of Mann-Whitney test. Right bottom, correlation of the percentage of naïve/stem memory $C D 4 T_{H D}$ cells with objective responses in G1 patients by a Fisher's exact test. $(\boldsymbol{F})$ Scatter plot of the percentage of baseline CD4 $T_{H D}$ cells according to tumor expression levels as shown in the legend.

\section{Identification of responders by baseline $T_{\text {HD }}$ subset profiling and PD-L1 tumor status}

Identification of responders with a high probability prior to therapy is currently a major challenge. In this study, all responders belonged to G1 patients and presented a specific $\mathrm{T}_{\mathrm{HD}}$ fingerprint consisting of higher numbers of naïve/stem memory CD4 $\mathrm{T}_{\mathrm{HD}}$ cells compared to $\mathrm{G} 1$ non-responders $(\mathrm{P}=0.03)$ (Fig. 6E). There was a very significant association between G1 patients with naïve/stem memory $\mathrm{T}_{\mathrm{HD}}$ cells above $5 \%$ and objective responses $(\mathrm{P}=0.003)$.

PD-L1 tumor expression levels could be evaluated in 21 of the patients before therapy, and did not significantly correlate with baseline $\mathrm{T}_{\mathrm{HD}} \mathrm{G} 1$ or $\mathrm{G} 2$ profiles $(\mathrm{P}=0.1)$. PD-L1 expression correlated with objective responses at the limit of statistical significance in our cohort study when used as a single stratifying factor $(\mathrm{P}=0.052$ by Fisher's exact test) (data not shown). PDL1 tumor expression seemed to segregate G1 patients into responders and nonresponders (Fig. 6F), in our limited cohort of patients in whom PD-L1 tumor expression levels could be evaluated. There was a tendency for G1 responder patients compared to G1 non-responders to have higher PD-L1 tumor expression prior to therapy. These results suggested that patients with baseline naïve/stem memory $\mathrm{T}_{\mathrm{HD}}$ cells above 5\% together with PD-L1 tumor positivity may accurately identify responders amongst the G1 patient population.

\section{Discussion}

Our data shows that the efficacy of PDL1/PD-1 blockade monotherapies in metastasic NSCLC patients heavily relies on systemic CD4 $\mathrm{T}_{\mathrm{HD}}$ cell numbers. Importantly, we are unequivocally identifying patients in our clinical practice with primary resistance and a high risk of hyperprogressive disease before enrolment, by quantification of $\mathrm{T}_{\mathrm{HD}}$ cells from routine small blood samples. While there has been a recent output of potential biomarkers from blood sampling, most of them have prognostic value rather than predictive capacities, while others are rather challenging to implement in routine clinical practice.

CD8 $T$ cell subsets were extensively studied with similar results as reported (Kamphorst et al., 2017) but without practical stratification capacities. The CD8 $\mathrm{T}$ cell response was delayed and followed CD4 $\mathrm{T}_{\mathrm{HD}}$ dynamic changes but at a lesser extent. Therefore, CD8 T cell monitoring had a lack of practical predictive capacities. Initially, we hypothetized that CD4 $\mathrm{T}_{\mathrm{HD}}$ cells in cancer patients were senescent, terminally-differentiated $\mathrm{T}$ cells, a subset strongly associated to the EMRA phenotype (Lanna et al., 2017; Lanna et al., 2014). To our surprise, CD4 $\mathrm{T}_{\mathrm{HD}}$ cells in 
cancer patients were enriched in central and effector memory subtypes, strongly suggesting that $\mathrm{T}_{\mathrm{HD}}$ cells did not reach terminal differentiation. Indeed, CD4 $\mathrm{T}_{\mathrm{HD}}$ cells expressed high levels of Ki67, suggesting that they were proliferating in cancer patients. This raises the question of whether reduced $\mathrm{CD} 28$ and $\mathrm{CD} 27$ expression in $\mathrm{T}$ cells is a true hallmark of $\mathrm{T}$ cell senescence, at least in lung cancer patients. Nevertheless, the more differentiated CD4 $\mathrm{T}$ cell subsets in lung cancer patients strongly co-expressed PD-1 and LAG3 after stimulation compared to CD28+ CD27+ T cells. This suggests that the systemic pool of differentiated CD4 T cells is dysfunctional in patients, and prone to inactivation by PD-L1/PD-1 interactions. NSCLC patients were separated in two distinct groups according to baseline CD4 $\mathrm{T}_{\mathrm{HD}}$ numbers, strongly suggesting that lung cancer patients had diametrically different immunological responses to cancer. Responder patients presented significantly higher CD4 $\mathrm{T}_{\mathrm{HD}}$ baseline numbers which may represent a pre-existing large pool of antigen-specific central and effector memory $\mathrm{T}$ cells with potential anti-tumor capacities. Responders showed decreases in circulating CD4 $\mathrm{T}_{\mathrm{HD}}$ cells following antibody administration, which may indicate either a recovery of CD28-CD27 expression, or mobilization from peripheral blood to secondary lymphoid organs/tumor sites. In contrast, a systemic expansion of central memory $\mathrm{T}_{\mathrm{HD}}$ cells (most likely through active proliferation) was always

\section{Materials and Methods}

\section{Study Design}

The study was approved by the Ethics Committee at the Hospital Complex of Navarre, and strictly followed the principles of the Declaration of Helsinki associated to non-responders which was plainly apparent in hyperprogressors. A negative baseline profile associated to " $\mathrm{T}_{\mathrm{HD}}$ bursts" accurately correlate with hyperprogressive disease in NSCLC without the need of obtaining radiological evidence, which supports hyperprogression as a true phenomenon with a biological basis.

According to our results in our cohort study, NSCLC patients with a negative baseline profile (G2 patients) do not respond to PD-L1/PD-1 immune checkpoint blockade monotherapy. Their identification prior to therapy helps avoiding the enrolment of hyperprogressors and intrinsic non-responders. Of the remaining patients, quantification of CD4 $\mathrm{T}_{\mathrm{HD}}$ cells with naïve/stem memory phenotypes coupled to tumor expression of PD-L1 can help identifying responders with accuracy. Nevertheless, administration of therapy would not be indicated if $\mathrm{T}_{\mathrm{HD}}$ bursts are observed following the first cycle of therapy.

$\mathrm{T}_{\mathrm{HD}}$ profiling can be performed in patients some time before enrolment into immunotherapies without necessarily quantifying this subset right before starting therapy. Indeed, our immunological profiling helps to make objective decisions regarding NSCLC patients under PDL1/PD-1 blockade, and places CD4 T cell responses at the center of anti-tumor immunity.

and Good Clinical Practice guidelines. Written informed consent was obtained from each participant, and samples were collected by the Blood and Tissue Bank of Navarre, Health Department of Navarre, Spain. 27 patients diagnosed with nonsquamous and 7 with squamous NSCLC were recruited at the Hospital Complex of Navarre (Table S1 in supplementary 
material). Patients had all progressed to first line chemotherapy or concurrent chemo-radiotherapy. Eligible patients were 18 years of age or older who agreed to receive immunotherapy targeting PD1/PD-L1 following the current indications (table S1). Tumor PD-L1 expression could be quantified in 21 of these patients before the start of therapies. Measurable disease was not required. The exclusion criteria consisted on concomitant administration of chemotherapy or previous immunotherapy treatment. NSCLC patients had an age of $64.8 \pm 8.3$ (mean \pm standard deviation, S.D., $\mathrm{N}=45$ ). Age-matched healthy donors were recruited from whom written informed consent was also obtained, with an age of $68.60 \pm 8$ (mean \pm S.D., $N=40$ ).

Therapy with nivolumab, pembrolizumab and atezolizumab was provided following current indications (Herbst et al., 2016; Horn et al., 2017; Rittmeyer et al., 2017). 4 $\mathrm{ml}$ peripheral blood samples were obtained prior and during immunotherapy before administration of each cycle. PBMCs were isolated as described (Escors et al., 2008) and $\mathrm{T}$ cells analysed by flow cytometry. The participation of each patient concluded when a radiological test confirmed response or progression, with the withdrawal of consent or after death of the patient. Tumor responses were evaluated according to RECIST 1.1 (Eisenhauer et al., 2009) and Immune-Related Response Criteria (Wolchok et al., 2009). Hyperprogression was identified by the criteria proposed by Saada-Bouzid et al. (Champiat et al., 2017; Saada-Bouzid et al., 2017). Objective responses were confirmed by at least one sequential tumor assessment.

\section{Flow cytometry}

Surface and intracellular flow cytometry analyses were performed as described (Gato-Canas et al., 2017; Karwacz et al., 2011). T cells were immediately isolated and stained. $4 \mathrm{ml}$ blood samples were collected from each patient, and PBMCs isolated by FICOL gradients right after the blood extraction. PBMCs were washed and cells immediately stained with the indicated antibodies in a final volume of $50 \mu \mathrm{l}$ for 10 min in ice. Cells were washed twice, resuspended in $100 \mu \mathrm{l}$ of PBS and analyzed immediately. The following fluorochromeconjugated antibodies were used at the indicated dilutions: CD4-FITC (clone MT466, reference 130-080-501, Miltenyi Biotec), CD4-APC-Vio770 (clone MT466, reference 130-100-455, Miltenyi Biotec), CD4-PECy7 (clone SK3, reference 4129769, BD Biosciences,) CD27-APC (clone M-T271, reference 130-097-922, Miltenyi Biotec), CD27-PE (clone MT271, reference 130-093-185, Miltenyi Biotec), CD45RA-FITC (reference 130098-183, Miltenyi Biotec), CD62L-APC (reference 130-099-252, Miltenyi Biotech), CD28-PECy7 (clone CD28.2, reference 302926, Biolegend), PD-1-PE (clone EH12.2H7, reference 339905, Biolegend), CD8-FITC (clone SDK1, reference 344703, Biolegend), CD8-APC-Cy7(clone RFT-8, reference A15448, Molecular probes by Life technologies).

\section{Cell culture}

Human lung adenocarcinoma A549 cells were a kind gift of Dr Ruben Pio, and were grown in standard conditions. These cells were modified with a lentivector encoding a single-chain version of a membrane bound anti-OKT3 antibody.

\section{Spanning-tree progression analysis of} density-normalized events (SPADE)

Flow cytometry data was analyzed with SPADE v3 (Qiu et al., 2011) using forward, scatter, CD4, CD28 and CD27 expression as overlapping markers for cell clustering. Arcsinh with cofactor of 150 was used for data transformation, from a maximum of 100000 events and 30 clusters.

\section{Data collection and Statistics}

$\mathrm{T}$ cell percentages were quantified using Flowjo (Lanna et al., 2017; Lanna et al., 2014). The percentage of CD4/CD8 $\mathrm{T}_{\mathrm{HD}}$ (CD28 and CD27 double-negative) and poorly differentiated $\mathrm{T}$ cells (CD28+ 
CD27+) were quantified prior to therapy (baseline), and before administration of each cycle of therapy. Gates in flow cytometry density plots were established taking non-senescent $\mathrm{T}$ cells as a reference. Data was recorded by M.Z.I., and separately analyzed thrice by M.Z.I. and H.A.E. independently. Cohen's kappa coefficient was utilized to test the interrater agreement in classification of immunological profiles $(\kappa=0.939)$.

The mode of action, pharmacokinetics, adverse events and efficacies of the three PD-L1/PD-1 blocking agents are comparable in NSCLC, which act through the interference with the inhibitory interaction between PD-L1 and PD-1 (Herbst et al., 2016; Horn et al., 2017; Rittmeyer et al., 2017). Treatments administered to the patients were allocated strictly on the basis of their current indications, and independently of any variable under study. Hence, in the study design the use of all data was pre-specified to be pooled to enhance statistical power, and thereby reducing type I errors from testing the hypotheses after had hoc subgrouping into specific PD-L1/PD-1 blockers. The number of patients assured statistical power for Fisher's exact test of 0.95 and superior for Student $t$ and MannWhitney tests ( $\mathrm{G}^{*}$ Power calculator) (Faul et al., 2009), taking into account that the expected proportion of responders using any of the three PD-L1/PD-1 immune checkpoint blockade drugs in NSCLC is around $20 \%$ to $25 \%$ (if no stratification using PD-L1 tumor expression levels is used) (Herbst et al., 2016; Horn et al., 2017; Rittmeyer et al., 2017). Our study confirmed the therapeutic efficacy of these agents by achieving a $20 \%$ response rate.

Two pre-specified subgroup analyses in the study were contemplated. The first, baseline T cell values; the second, post-first cycle $\mathrm{T}$ cell changes from baseline. The study protocol contemplated the correlation of these values with responses using Fisher's exact test, paired Student $t$ tests/repeated measures ANOVA (if normally distributed) or $\mathrm{U}$ of MannWhitney/Kruskal-Wallis (if not normally distributed, or data with intrinsic high variability) to be correlated with responses. Two-tailed tests were applied with the indicated exceptions (see below). Importantly, the treatment administered to the patients was allocated independently of their basal immunological profiles, and strictly followed the current indications for the PD-L1/PD-1 inhibitors.

The percentage of $\mathrm{T}$ cell subsets in untreated cancer patients was normally distributed (Kolmogorov-Smirnov normality test), but not in age-matched healthy donors. Hence, to compare $\mathrm{T}$ cell values between two independent cancer patient groups, two-tailed unpaired Student $t$ tests were used while comparisons between healthy subjects and cancer patients were carried out with the $U$ of Mann-Whitney. The mean age of cancer patients and healthy donors was $64.8 \pm 8.3$ (S.D.) and $68.60 \pm 8$ (S.D.), respectively. Percentages of $\mathrm{T}$ cell populations in treated patients were not normally distributed, so response groups were compared with either Mann-Whitney (comparisons between two independent groups) or Kruskall-Wallis for multi-comparison tests if required and as indicated in the manuscript. To confirm the increase or decrease in $\mathrm{T}_{\mathrm{HD}}$ cells between baseline and post-first cycle of therapy in either responders or non-responders, onetailed paired $t$ tests were carried out. To test changes in $\mathrm{Ki} 67$ expression in $\mathrm{T}$ cells between baseline and post-first cycle of therapy in either responders or nonresponders, two-tailed paired t tests were carried out. Fisher's exact test was used to assess the association between CD4 $\mathrm{T}_{\mathrm{HD}}$ dynamic profiles or the baseline values of $\mathrm{T}_{\mathrm{HD}}$ cells with clinical responses. Post hoc Cohen's kappa coefficient test was used to test the agreement of radiological versus immunological criteria for the identification of hyperprogressors.

Progression free survival (PFS) was defined as the time from the starting date of therapy to the date of disease progression or the date 
of death by any cause, whichever occurred first. PFS was censored on the date of the last tumor assessment demonstrating absence of progressive disease in progression-free and alive patients. PFS rates at 12 and 28-weeks was estimated as the proportion of patients who were free-ofdisease progression and alive at 12 and 28 weeks after the initiation of immunotherapies. Patients who dropped out for worsening of disease and did not have a 28-week tumor assessment were considered as having progressive disease. Overall response rate (ORR) was the proportion of patients who achieved best overall response of complete or partial responses.

PFS was represented by Kaplan-Meier plots and long-rank tests utilized to compare cohorts. Hazard ratios were estimated by Cox regression models. For PFS analyses, patients were pre-specified to be stratified only on the basis of their basal $\mathrm{T}_{\mathrm{HD}}$ values to avoid increase in type I errors due to multiplicity by subgroup analyses. Receiver operating characteristic (ROC) analysis was performed with baseline $\mathrm{T}_{\mathrm{HD}}$ numbers and response/non-response as a binary output. Statistical tests were performed with GraphPad Prism 5 and SPSS statistical packages.

\section{References}

Azuma, T., Yao, S., Zhu, G., Flies, A. S., Flies, S. J., and Chen, L. (2008). B7-H1 is a ubiquitous antiapoptotic receptor on cancer cells. Blood 111, 3635-3643.

Brahmer, J. R., Tykodi, S. S., Chow, L. Q., Hwu, W. J., Topalian, S. L., Hwu, P., Drake, C. G., Camacho, L. H., Kauh, J., Odunsi, K., et al. (2012). Safety and activity of anti-PD-L1 antibody in patients with advanced cancer. N Engl J Med 366, 2455-2465.

Champiat, S., Dercle, L., Ammari, S., Massard, C., Hollebecque, A., Postel-Vinay, S., Chaput, N., Eggermont, A., Marabelle, A., Soria, J. C., and Ferte, C. (2017). Hyperprogressive Disease Is a New Pattern of Progression in Cancer Patients Treated by Anti-PD-1/PD-L1. Clin Cancer Res 23, 1920-1928.

Chemnitz, J. M., Parry, R. V., Nichols, K. E., June, C. H., and Riley, J. L. (2004). SHP-1 and SHP-2 associate with immunoreceptor tyrosine-based switch motif of programmed death 1 upon primary human $\mathrm{T}$ cell stimulation, but only receptor ligation prevents $\mathrm{T}$ cell activation. J Immunol 173, 945-954.

Eisenhauer, E. A., Therasse, P., Bogaerts, J., Schwartz, L. H., Sargent, D., Ford, R., Dancey, J., Arbuck, S., Gwyther, S., Mooney, M., et al. (2009). New response evaluation criteria in solid tumours: revised RECIST guideline (version 1.1). Eur $\mathrm{J}$ Cancer 45, 228-247.

Escors, D., Lopes, L., Lin, R., Hiscott, J., Akira, S., Davis, R. J., and Collins, M. K. (2008). Targeting dendritic cell signalling to regulate the response to immunisation. Blood 111, 3050-3061.

Faul, F., Erdfelder, E., Buchner, A., and Lang, A. G. (2009). Statistical power analyses using G*Power 3.1: tests for correlation and regression analyses. Behavior research methods 41, 1149-1160.

Galon, J., Costes, A., Sanchez-Cabo, F., Kirilovsky, A., Mlecnik, B., Lagorce-Pages, C., Tosolini, M., Camus, M., Berger, A., Wind, P., et al. (2006). Type, density, and location of immune cells within human colorectal tumors predict clinical outcome. Science 313, 1960-1964.

Gato-Canas, M., Zuazo, M., Arasanz, H., IbanezVea, M., Lorenzo, L., Fernandez-Hinojal, G., Vera, R., Smerdou, C., Martisova, E., Arozarena, I., et al. (2017). PDL1 Signals through Conserved Sequence Motifs to Overcome Interferon-Mediated Cytotoxicity. Cell Rep 20, 1818-1829.

Grigg, C., and Rizvi, N. A. (2016). PD-L1 biomarker testing for non-small cell lung cancer: truth or fiction? Journal for immunotherapy of cancer 4,48 .

Henson, S. M., Macaulay, R., Riddell, N. E., Nunn, C. J., and Akbar, A. N. (2015). Blockade of PD-1 or p38 MAP kinase signaling enhances senescent human $\mathrm{CD} 8(+) \mathrm{T}$-cell proliferation by distinct pathways. Eur J Immunol 45, 1441-1451.

Herbst, R. S., Baas, P., Kim, D. W., Felip, E., PerezGracia, J. L., Han, J. Y., Molina, J., Kim, J. H., Arvis, C. D., Ahn, M. J., et al. (2016). Pembrolizumab versus docetaxel for previously treated, PD-L1-positive, advanced non-small-cell lung cancer (KEYNOTE-010): a randomised controlled trial. Lancet 387, 1540-1550.

Horn, L., Spigel, D. R., Vokes, E. E., Holgado, E., Ready, N., Steins, M., Poddubskaya, E., Borghaei, H., Felip, E., Paz-Ares, L., et al. (2017). Nivolumab Versus Docetaxel in Previously Treated Patients With Advanced Non-Small-Cell Lung Cancer: Two- 
Year Outcomes From Two Randomized, OpenLabel, Phase III Trials (CheckMate 017 and CheckMate 057). J Clin Oncol 35, 3924-3933.

Jamieson, N. B., and Maker, A. V. (2017). Geneexpression profiling to predict responsiveness to immunotherapy. Cancer Gene Ther 24, 134-140.

Juneja, V. R., McGuire, K. A., Manguso, R. T., LaFleur, M. W., Collins, N., Haining, W. N., Freeman, G. J., and Sharpe, A. H. (2017). PD-L1 on tumor cells is sufficient for immune evasion in immunogenic tumors and inhibits CD8 T cell cytotoxicity. J Exp Med 214, 895-904.

Kamphorst, A. O., Pillai, R. N., Yang, S., Nasti, T. H., Akondy, R. S., Wieland, A., Sica, G. L., Yu, K., Koenig, L., Patel, N. T., et al. (2017). Proliferation of PD-1+ CD8 T cells in peripheral blood after PD1-targeted therapy in lung cancer patients. Proceedings of the National Academy of Sciences of the United States of America 114, 4993-4998.

Karwacz, K., Bricogne, C., Macdonald, D., Arce, F., Bennett, C. L., Collins, M., and Escors, D. (2011). PD-L1 co-stimulation contributes to ligand-induced $\mathrm{T}$ cell receptor down-modulation on CD8(+) T cells. EMBO Mol Med 3, 581-592.

Lanna, A., Gomes, D. C., Muller-Durovic, B., McDonnell, T., Escors, D., Gilroy, D. W., Lee, J. H., Karin, M., and Akbar, A. N. (2017). A sestrindependent Erk-Jnk-p38 MAPK activation complex inhibits immunity during aging. Nat Immunol 18 , 354-363.

Lanna, A., Henson, S. M., Escors, D., and Akbar, A. N. (2014). The kinase p38 activated by the metabolic regulator AMPK and scaffold TAB1 drives the senescence of human T cells. Nat Immunol 15, 965972.

Qiu, P., Simonds, E. F., Bendall, S. C., Gibbs, K. D., Jr., Bruggner, R. V., Linderman, M. D., Sachs, K., Nolan, G. P., and Plevritis, S. K. (2011). Extracting a cellular hierarchy from high-dimensional Acknowledgments

We sincerely thank the patients and families that generously agreed to take part in this study. We are thankful to Drs Luis Montuenga and Ruben Pio for their constructive comments and input.

\section{Funding}

This research was supported by Asociación Española Contra el Cáncer (AECC, PROYE16001ESCO); Instituto de Salud Carlos III, Spain (FIS project grant PI17/02119), a "Precipita" Crowdfunding cytometry data with SPADE. Nature biotechnology 29, 886-891.

Rittmeyer, A., Barlesi, F., Waterkamp, D., Park, K., Ciardiello, F., von Pawel, J., Gadgeel, S. M., Hida, T., Kowalski, D. M., Dols, M. C., et al. (2017). Atezolizumab versus docetaxel in patients with previously treated non-small-cell lung cancer (OAK): a phase 3, open-label, multicentre randomised controlled trial. Lancet 389, 255-265.

Saada-Bouzid, E., Defaucheux, C., Karabajakian, A., Coloma, V. P., Servois, V., Paoletti, X., Even, C., Fayette, J., Guigay, J., Loirat, D., et al. (2017). Hyperprogression during anti-PD-1/PD-L1 therapy in patients with recurrent and/or metastatic head and neck squamous cell carcinoma. Ann Oncol 28, 1605-1611.

Topalian, S. L., Hodi, F. S., Brahmer, J. R., Gettinger, S. N., Smith, D. C., McDermott, D. F., Powderly, J. D., Carvajal, R. D., Sosman, J. A., Atkins, M. B., et al. (2012). Safety, activity, and immune correlates of anti-PD-1 antibody in cancer. N Engl J Med 366, 2443-2454.

Topalian, S. L., Taube, J. M., Anders, R. A., and Pardoll, D. M. (2016). Mechanism-driven biomarkers to guide immune checkpoint blockade in cancer therapy. Nature reviews 16, 275-287.

Vranic, S. (2017). Microsatellite instability status predicts response to anti-PD-1/PD-L1 therapy regardless the histotype: A comment on recent advances. Bosnian journal of basic medical sciences 17, 274-275.

Wolchok, J. D., Hoos, A., O'Day, S., Weber, J. S., Hamid, O., Lebbe, C., Maio, M., Binder, M., Bohnsack, O., Nichol, G., et al. (2009). Guidelines for the evaluation of immune therapy activity in solid tumors: immune-related response criteria. Clin Cancer Res 15, 7412-7420.

grant (FECYT). D.E. is funded by a Miguel Servet Fellowship (ISC III, CP12/03114, Spain); M.Z.I. is supported by a scholarship from Universidad Pública de Navarra; H.A. is supported by a scholarship from AECC; M.G.C. is supported by a scholarship from the Government of Navarre.

\section{Author contributions}

M.Z.I. designed and carried out experiments, collected data, analyzed data. H.A.E. designed and carried out experiments, collected data, analyzed data. 
G.F.H. recruited patients, collected data, analyzed clinical data. M.G.C. carried out experiments, collected data, analyzed data. B.H.M. recruited patients, collected data, analyzed clinical data. M.M.A. recruited patients, collected data, analyzed clinical data. M.J.L. recruited patients, collected data, analyzed clinical data. A.F. recruited patients, collected data, analyzed clinical data. L.T. recruited patients, collected data, analyzed clinical data. R.V. supervised the clinical staff, recruited patients, analyzed clinical data. G.K. conceived the project, supervised non-clinical researchers, analysed data and wrote the paper. D.E. conceived the project, supervised nonclinical researchers, analysed data and wrote the paper. All authors participated in the writing of the manuscript.

\section{Competing interests:}

The authors declare no competing interests. 


\section{Supplementary Materials}

Table S1. Baseline patient characteristics

\begin{tabular}{|c|c|}
\hline CHARACTERISTIC & $\begin{array}{l}\text { Non-Small Cell Lung } \\
\text { Cancer }(\mathbf{N}=\mathbf{3 4})\end{array}$ \\
\hline $\begin{array}{l}\text { Age category - no. }(\%) \\
41-50 \\
51-60 \\
61-70 \\
71-80 \\
>80 \\
\end{array}$ & $\begin{array}{l}1(2.9 \%) \\
10(29.4 \%) \\
15(44.1 \%) \\
7(20.6 \%) \\
1(2.9 \%) \\
\end{array}$ \\
\hline $\begin{array}{l}\text { Sex }- \text { no. }(\%) \\
\text { Male } \\
\text { Female }\end{array}$ & $\begin{array}{l}25(73.5 \%) \\
9(26.5 \%)\end{array}$ \\
\hline $\begin{array}{l}\text { ECOG Performance-status score }- \text { no. }(\%) \\
0-1 \\
2-4\end{array}$ & $\begin{array}{l}26(76.5 \%) \\
8(23.5 \%)\end{array}$ \\
\hline $\begin{array}{l}\text { Smoking habit - no. }(\%) \\
\text { Yes } \\
\text { No }\end{array}$ & $\begin{array}{l}31(91.2 \%) \\
3(8.8 \%) \\
\end{array}$ \\
\hline $\begin{array}{l}\text { Metastases location }- \text { no. }(\%) \\
\text { Lymph nodes } \\
\text { Viscera } \\
\text { Both }\end{array}$ & $\begin{array}{l}3(8.8 \%) \\
3(8.8 \%) \\
28(82.4 \%) \\
\end{array}$ \\
\hline $\begin{array}{l}\text { Immunotherapy - no. }(\%) \\
\text { Pembrolizumab } \\
\text { Nivolumab } \\
\text { Atezolizumab }\end{array}$ & $\begin{array}{l}4(11.8 \%) \\
13(38.2 \%) \\
17(50 \%) \\
\end{array}$ \\
\hline $\begin{array}{l}\text { Treatments received during } 3 \text { months prior to } \\
\text { immunotherapy - no. }(\%) \\
\text { Platinum-based chemotherapy } \\
\text { Other chemotherapy } \\
\text { Concurrent chemoradiotherapy } \\
\text { Radiotherapy } \\
\text { Targeted therapies } \\
\text { None }\end{array}$ & $\begin{array}{l}11(32.3 \%) \\
12(35.3 \%) \\
1(2.9 \%) \\
2(5.9 \%) \\
0(0 \%) \\
8(23.5 \%) \\
\end{array}$ \\
\hline $\begin{array}{l}\text { Lymphocyte count }- \text { no. }(\%) \\
<1.5 \times 10^{9} / \mathrm{L} \\
1.5-4.0 \times 10^{9} / \mathrm{L}\end{array}$ & $\begin{array}{l}8(23.5 \%) \\
26(76.5 \%)\end{array}$ \\
\hline $\begin{array}{l}\text { Tumor PD-L1 expression - no. (\%) } \\
0 \% \\
1-4 \% \\
5-49 \% \\
\geq 50 \%\end{array}$ & $\begin{array}{l}9(26.5 \%) \\
4(12.8 \%) \\
4(12.8 \%) \\
5(14.7 \%)\end{array}$ \\
\hline
\end{tabular}


bioRxiv preprint doi: https://doi.org/10.1101/320176; this version posted May 22, 2018. The copyright holder for this preprint (which was not certified by peer review) is the author/funder. All rights reserved. No reuse allowed without permission.

\begin{tabular}{|l|l|}
\hline Non-evaluable & $12(35.3 \%)$ \\
\hline Baseline lymphocyte profile & \\
Disfavorable & $16(47 \%)$ \\
Non-disfavorable & $18(53.5 \%)$ \\
\hline
\end{tabular}

